\title{
Features of the Ionosphere around the Time of the 5th August, 2014 M5.5 Orkney Earthquake
}

\author{
Enoch Oluwaseun Elemo, Daniel Okoh \\ Centre for Atmospheric Research, Anyigba, Nigeria \\ Email: enochelemo@yahoo.com
}

Received 16 May 2015; accepted 2 June 2015; published 9 June 2015

Copyright (C) 2015 by authors and OALib.

This work is licensed under the Creative Commons Attribution International License (CC BY). http://creativecommons.org/licenses/by/4.0/

(c) (i) Open Access

\begin{abstract}
In this paper, presentation of specific features of TEC behaviour as a possible precursor of Orkney earthquake of August 5th, 2014 (M5.5) was made. To achieve this, TEC data from Suth station and GIM TEC maps were used. The period understudied (prior to and after the earthquake) experienced quiet geomagnetic situation which made the analysis much easier. A characteristic anomaly was noticed from 4 days before the earthquake and it was found out that the day-time TEC increases significantly and consistently relative to the background condition up to the day before the earthquake. To reveal the spatial dimensions of seismo-ionospheric anomaly longitudinally, the maps from IONEX database were used. The ionosphere, experiencing a modification as an increase of electron concentration over a large area, was revealed.
\end{abstract}

\section{Keywords}

Orkey Earthquake, GIM TEC Maps, Seismo-Ionospheric Anomaly

Subject Areas: Atmospheric Sciences, Geophysics

\section{Introduction}

The system of geophysical shells (lithosphere, atmosphere, and ionosphere) is considered as an open complex nonlinear system with dissipation where earthquake preparation could be regarded as a self-organizing process leading to the critical state of the system [1]. The processes in atmosphere together with ionosphere are considered from the point of view of non-equilibrium thermodynamics. The intensive ionization of boundary layer of atmosphere (probably provided by radon in occasion of earthquake preparation) gives start to the synergetic sequence of coupling processes where the ionosphere and even magnetosphere are the last links in the chain of interactions [1]. Every anomaly observed in different geophysical fields (surface temperature, latent heat flux, 
electromagnetic emissions, variations in ionosphere, particle precipitation, etc.) is not considered as an individual process but the part of the self-organizing process, the final goal of which is the reaching of the point of the maximum entropy. Seismo-ionospheric couplings studies had increased over the last decade with various important results to show. The global ionosphere maps (GIM) containing grid data of the vertical TEC, published by the ionospheric group of the international service of the global positioning system IGS, had received great attention in studying ionospheric phenomena [2]-[4]. Invariably, GIM has also been proved as a useful source of data to analyze earthquake-related TEC variations [5]-[12]. Ionospheric anomalies noticed were not only over the epicenter of the earthquake but also in the regions located eastward or westward from the vertical projection of the epicenter onto the ionosphere [13] [14].

The Orkney earthquake occurred on 5th August, 2014 in South Africa, but its effect was also felt in Botswana, Swaziland, Lesotho and Mozambique. The casualties included one death and 34 injured (Table 1).

\section{Experimental Data and Method of Processing}

Adopting Liu et al. method estimate the vertical TEC of the ionosphere over the epicenter of the earthquake helps to identify a seismic signal from the GPS-TEC data by [15] [16]. TEC data from Suth station in South Africa between 21th of July to 20th of August 2014 (31 days) were used for this study. These days are clearly 15 days before and 15 days after the day of the earthquake. The median $\mathrm{X}$ over the interval of 15 running days were calculated in addition with the associated inter-quartile between the lower quartile (LQ) and the upper quartile (UQ).

TEC anomalies were isolated by setting the:

$$
\begin{aligned}
& \text { Upper bound }(\mathrm{UB})=\mathrm{X}+1.5(\mathrm{UQ}-\mathrm{X}) \\
& \text { Lower bound }(\mathrm{LB})=\mathrm{X}+1.5(\mathrm{LQ}-\mathrm{X})
\end{aligned}
$$

The method stated that perturbations that are of earthquakes origin are detected if the observed TEC data lies outside of either the lower or upper bound. However, only anomalies that persisted for at least 3 hrs in a day were taken into consideration. The implication of this is that an anomaly can only be considered a seismic signal if and only if its value is above the lower/upper bounds for more than 3 hours in a day [15].

For further TEC analysis, applications of IONEX GIM data provided by NASA Crustal Dynamics Data Information System (ftp://cddisa.gsfc.nasa.gov/pub/gps/products/ionex) were used. This is an international network of GPS receivers IGS that provides global maps of TEC in the IONEX format having a resolution of $5^{\circ}$ and $2.5^{\circ}$ in longitude and latitude, respectively, with a step of $2 \mathrm{~h}$ in UT. To do TEC deviations estimation from the average value for the selected date (August 5th), maps of TEC were selected from IONEX database which were of the same universal time (1400UT) for the previous 15 days. Thereafter the maps were averaged for each point of the map according to the resolution in latitude and longitude of IONEX maps. Global TEC maps from 4days before the day of the earthquake to a day before it were taken from final result. Dst and Kp indexesbetween $21^{\text {th }}$ of July to $20^{\text {th }}$ of August 2014 were also used to check for geomagnetic situation of the period.

\section{Results}

Figure 1 showed the variations of upper/lower anomalies extracted from the 31 days of the TEC data. It can be seen that the lower anomalies existed throughout the whole data with the higher values of it occurring from 7 days before and continue for few days after the earthquake (represented by E). While the upper anomalies was also noticed 7 days to the day of the earthquake and continue for some days after. Figure 2 however showed an enhanced anomalies in the TEC values (when compared with other values) from 4 days to the day of the earthquake and peaking exactly a day before the earthquake. These anomalies continue for another 3 days after the

\begin{tabular}{|c|c|c|c|c|c|c|c|c|}
\hline S.N & Location & $\begin{array}{c}\text { Date of } \\
\text { earthquake }\end{array}$ & $\begin{array}{c}\text { Time of } \\
\text { earthquake }\end{array}$ & Intensity & $\begin{array}{l}\text { Focal } \\
\text { depth }\end{array}$ & $\begin{array}{c}\text { Ionosonde } \\
\text { station }\end{array}$ & $\begin{array}{l}\text { Location } \\
\text { of station }\end{array}$ & Casualties \\
\hline 1 & $\begin{array}{c}\text { Orkney } \\
26.9717^{\circ} \mathrm{S} \\
26.7094^{\circ} \mathrm{E}\end{array}$ & $\begin{array}{l}5 \text { August } \\
2014\end{array}$ & 12:22:33 LT & $\begin{array}{c}5.5 \\
(\mathrm{KRV})\end{array}$ & $5.0 \mathrm{~km}$ & Sutherland & $\begin{array}{l}32.22^{\circ} \mathrm{S} \\
20.48^{\circ} \mathrm{E}\end{array}$ & $\begin{array}{c}1 \text { dead } \\
34 \text { injured }\end{array}$ \\
\hline
\end{tabular}

Table 1. Characteristics of Orkney earthquake. 


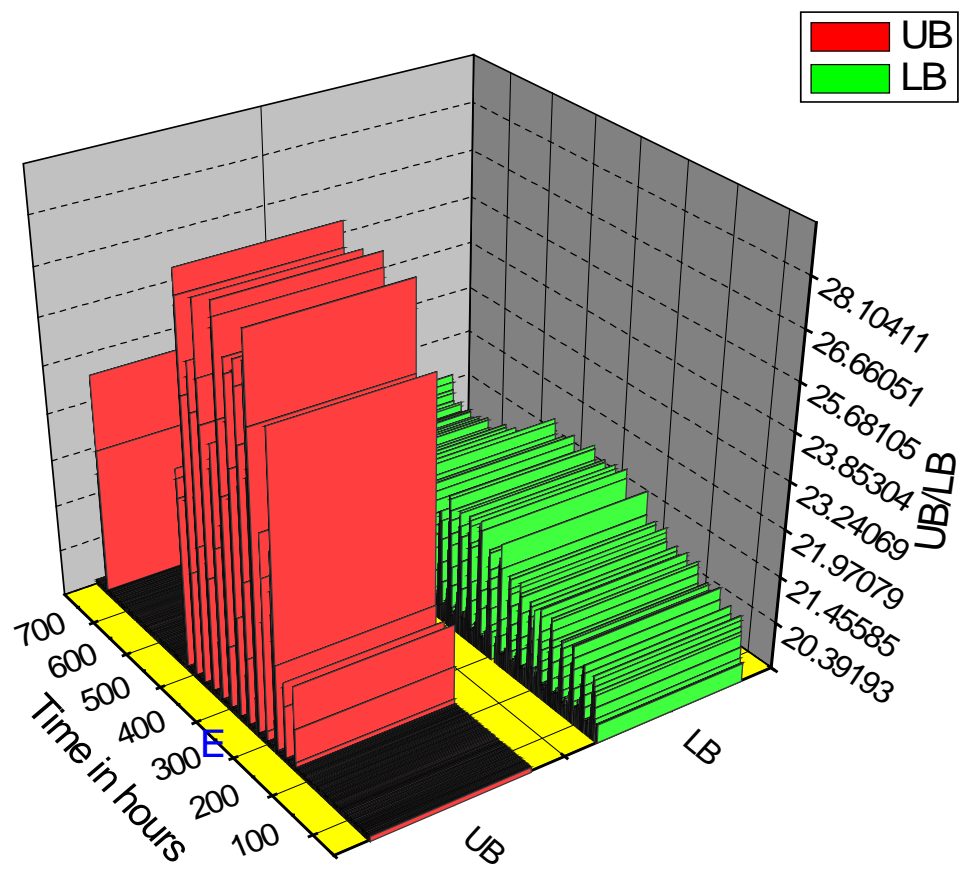

Figure 1. Lower and Upper anomalies for the 31 days understudy.

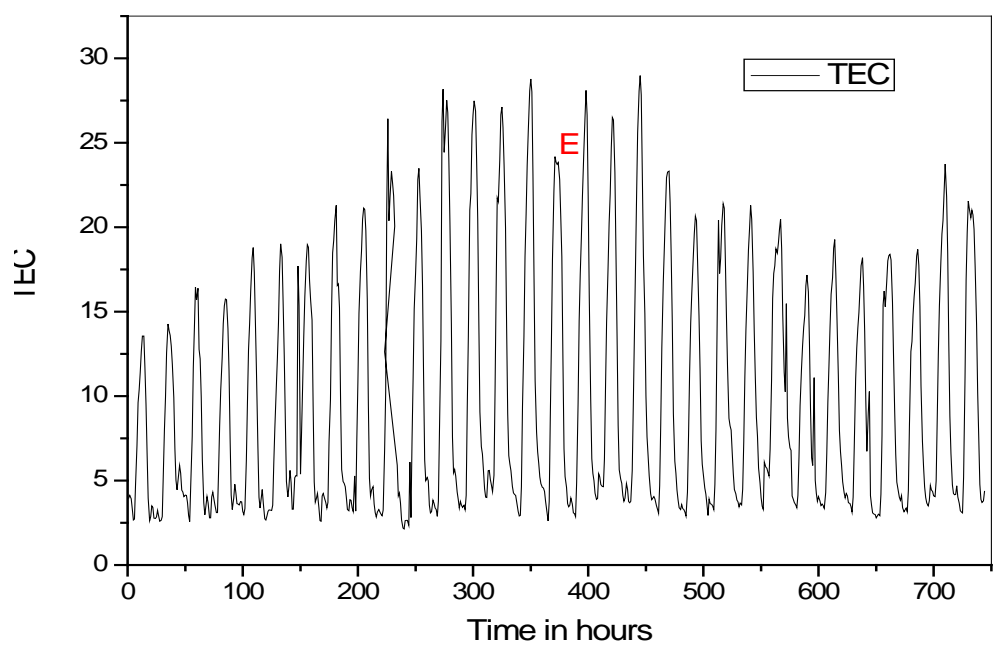

Figure 2. GPS TEC variation between $21^{\text {st }}$ of July and $20^{\text {th }}$ of August, 2014 of Suth station.

earthquake but with the peak value on the day of the earthquake clearly the least during that period. Figure 3 and Figure 4 made it very clear that the considered period of time was characterized by a quiet geomagnetic situation. Figure 5 reveals the TEC data (between 10:00 hrs and 14:00 hrs) 5 days before the earthquake and 4 days after. The graph clearly showed an enhanced anomalies which started 4 days before and peaked a day before the earthquake (represented by blue circle). The star represents the day of the earthquake. Another very obvious point from the graph is that the anomalous increase in the GPS TEC tends to be more pronounced in the afternoon of the days understudy. Figure 6 however showed the map of the TEC at 14:00UT (16:00LT) extracted from the GIM according to the process described above. It is clear that there exist an increase in the electron concentration in the longitudinal direction of the region of interest. Cloud-like increase in electron concentration was noticed building-up few days before the earthquake. The amplitude of modification significantly increase more within the vicinity of the epicentre two days to the earthquake. 


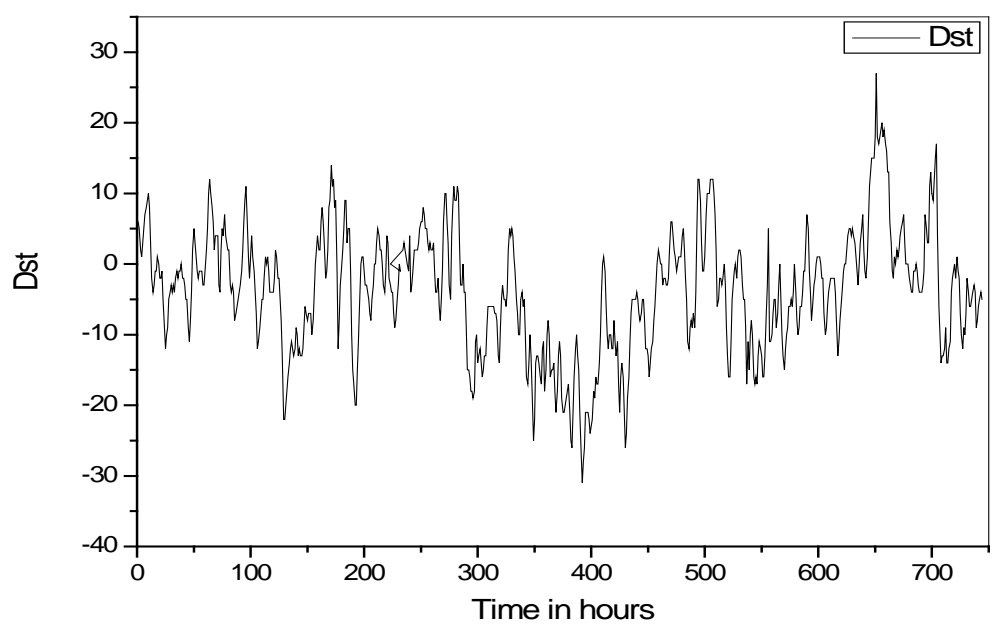

Figure 3. Dst index of the period under observation.

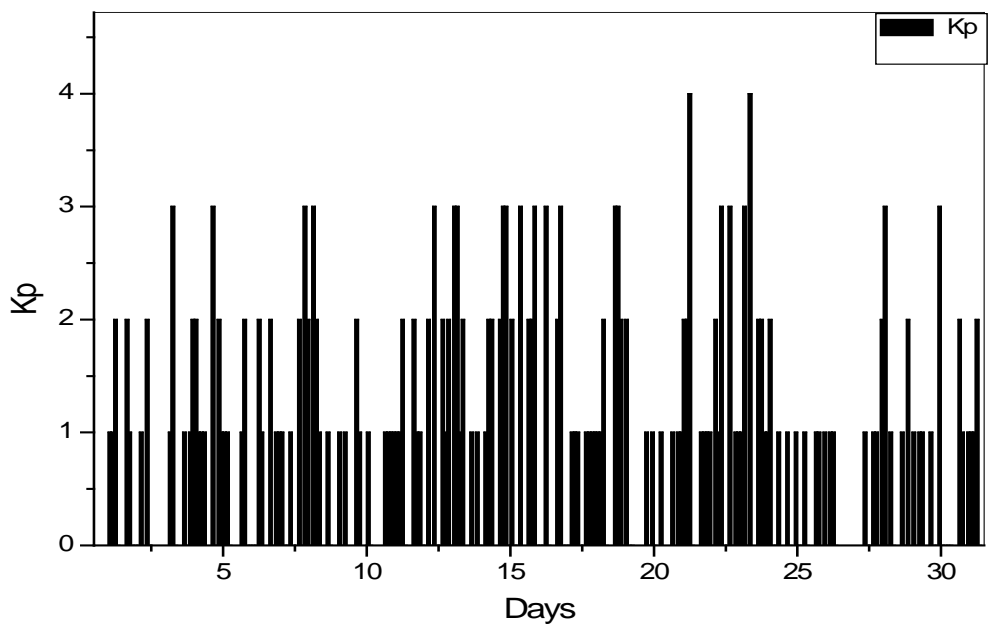

Figure 4. Kp for the period under observation.

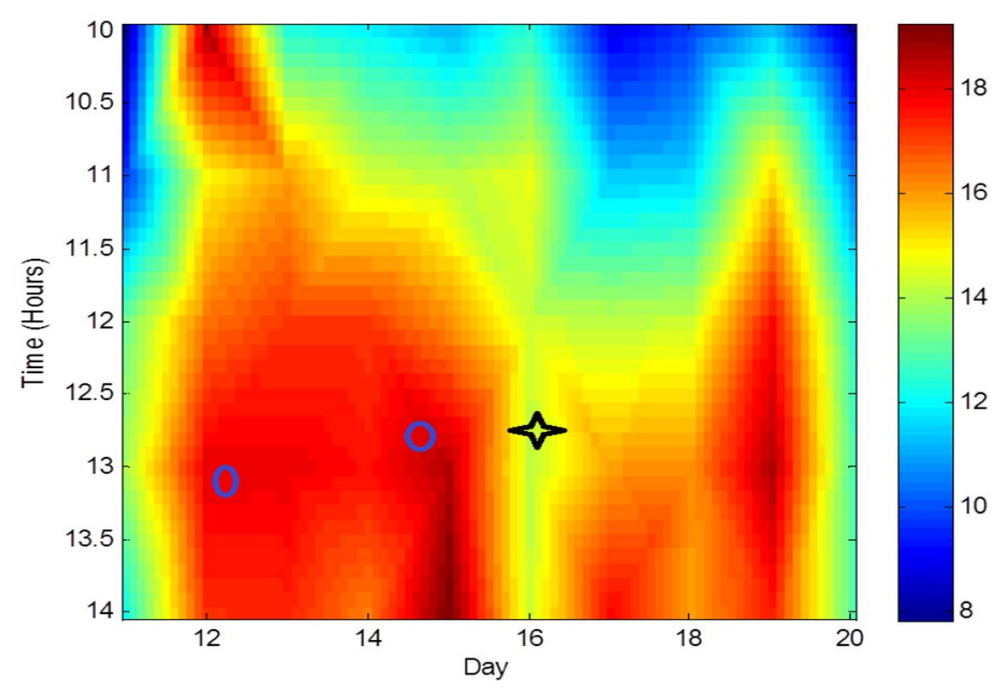

Figure 5. GPS TEC variation from 10:00 hrs to 14:00 hrs from day 11 to day 20 of the period under observational. 


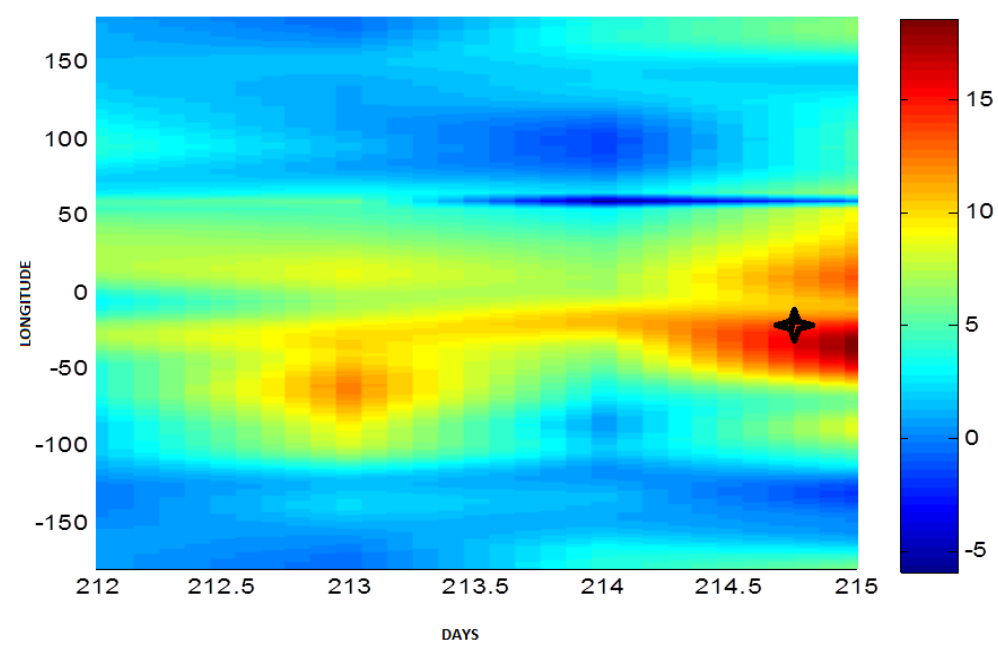

Figure 6. Map of TEC deviations from the running average for 4 days before the day of the earthquake at 1400 UT.

\section{Discussion}

The fact that both the occurrence of the upper anomalies and higher values of lower anomalies started and almost ended on the same day when geomagnetic activities throughout the whole period understudy were very obvious to be quiet, clearly show that the trigger of such situation was localized. "The trigger" can clearly be said to be of seismogenic origin. [17] emphasized that the spatial patterns of the anomalies resulting from seismic forcing differ from those perturbations induced by solar or geomagnetic activities which are usually registered on a global scale. Results from Figure 2 and Figure 5 show that the GPS TEC anomalously started increasing in the afternoon from day 12 of the data (4 days to the earthquake). This revealed the importance of seismo-generated vertical electric fields. [18]-[20] stated that anomalous vertical electric field near the earth surface well above the seismogenic area penetrates the ionosphere leading to irregularities of electron density by the ion drifting. However, [14] stated that the anomalous increase in the electron density is related to the downward electric field at the surface. [22] [23] observed in some of his works in Taiwan that the seismo-generated electric field (around the epicentre) can significantly decrease TEC in the afternoon of 1 - 5 days before earthquakes. He attributed this to the upward electric field at the surface. However, from the study, Both the local GPS receiver and the GIM TEC map clearly showed enhanced anomalies from 4 days to the day of the earthquake with it peaking on the day before it. In other words, the temporal variation and the spatial distribution of the normalized GPS TEC extracted from the GIM and the local GPS receiver showed that the seismo-ionospheric anomalies appeared on day $12,13,14$ and 15 of the days under study. These remarkable signatures can be attributed to the eastward plasma drift that led to the abnormal enhancement of the TEC in the longitudinal direction as described by [15].

\section{Conclusion}

Measurements from the GPS-TEC together with maps from IONOX database were used to study the total electron content changes in the ionosphere during the final stage of Orkney earthquake preparation time. The results of the analysis clearly showed that according to upper/lower anomalies, spatial and temporal distribution, the detected ionospheric anomaly was associated with the precursor of seismic activity.

\section{Acknowledgements}

Special appreciation goes to the Africa Geodetic Reference Frame (AFER) for providing the TEC data used for this work.

\section{References}

[1] Pulinets, S. (2011) The Synergy of Earthquake Precursors. Earthquake Science, 24, 535-548. 
http://dx.doi.org/10.1007/s11589-011-0815-1

[2] Mendillo, M., Huang, C.L., Pi, X., Rishbeth, H. and Meier, R. (2005) The Global Ionospheric Asymmetry in Total Electron Content. Journal of Atmospheric and Solar-Terrestrial Physics, 67, 1377-1387. http://dx.doi.org/10.1016/j.jastp.2005.06.021

[3] Afraimovich, E.L., Astafyeva, E.I., Oinats, A.V., Yasukevich, Y.V. and Zhivetiev, I.V. (2008) Global Electron Content: A New Conception to Track Solar Activity. Annales Geophysicae, 26, 335-344. http://dx.doi.org/10.5194/angeo-26-335-2008

[4] Hocke, K. (2008) Oscillations of Global Mean TEC. Journal of Geophysical Research, 113, A04302. http://dx.doi.org/10.1029/2007JA012798

[5] Kakinami, Y., Liu, J.Y., Tsai, L.C. and Oyama, K.-I. (2010) Ionospheric Electron Content Anomalies Detected by a FORMOSAT-3/COSMIC Empirical Model before and after the Wenchuan Earthquake. International Journal of Remote Sensing, 31, 3571-3578. http://dx.doi.org/10.1080/01431161003727788

[6] Zakharenkova, I.E., Krankowski, A. and Shagimuratov, I.I. (2006) Modification of the Low-Latitude 21 Ionosphere before December 26, 2004 Indonesian Earthquake. Natural Hazards and Earth System Sciences, 6, 817-823. http://dx.doi.org/10.5194/nhess-6-817-2006

[7] Zakharenkova, I.E., Shagimuratov, I.I., Tepenitzina, N.Yu. and Krankowski, A. (2008) Anomalous Modification of the Ionospheric Total Electron Content Prior to the September 26, 2005 Peru Earthquake. Journal of Atmospheric and Solar-Terrestrial Physics, 70, 1919-1928. http://dx.doi.org/10.1016/j.jastp.2008.06.003

[8] Astafyeva, E.I., Afraimovich, E.L., Oinats, A.V., Yasukevich, Y.V. and Zhivetiev, I.V. (2008) Dynamics of Global Electron Content in 1998-2005 Derived from Global GPS Data and IRI Modeling. Advances in Space Research, 42, 763-769. http://dx.doi.org/10.1016/j.asr.2007.11.007

[9] Zhao, B., Wang, M. and Yu, T. (2008) Is an Unusual Large Enhancement of Ionospheric Electron Density Linked with the 2008 Great Wenchuan Earthquake? Journal of Geophysical Research A, 113, Article ID: A11304, p. 6.

[10] Liu, L., Zhao, B., Wan, W., Ning, B., Zhang, M.L. and He, M. (2009) Seasonal Variations of the Ionospheric Electron Densities Retrieved from Constellation Observing System for Meteorology, Ionosphere, and Climate Mission adio Occultation Measurements. Journal of Geophysical Research, 114, A02302. http://dx.doi.org/10.1029/2008JA013819

[11] Yu, T., Wan, W.X., Liu, L.B. and Zhao, B.Q. (2004) Global Scale Annual and Semiannual Variations of Daytime NmF2 in the High Solar Activity Years. Journal of Atmospheric and Solar-Terrestrial Physics, 66, 1691-1701. http://dx.doi.org/10.1016/j.jastp.2003.09.018

[12] Pulinets, S.A., Bondur, V.G., Tsidilina, M.N. and Gaponova, M.V. (2010) Verification of the Concept of Seismoionospheric Coupling under Quiet Heliogeomagnetic Conditions, Using the Wenchuan (China) Earthquake of May 12, 2008, as an Example. Geomagnetism and Aeronomy, 50, 231-242. http://dx.doi.org/10.1134/S0016793210020118

[13] Namgaladze, A.A., Klimenko, M.V., Klimenko, V.V. and Zakharenkova, I.E. (2009) Physical Mechanism and Mathematical Simulation of Ionosphere Earthquake Precursors Observed in Total Electron Content. Geomagnetism and Aeronomy, 49, 252-262. http://dx.doi.org/10.1134/S0016793209020169

[14] Pulinets, S.A. (2009) Physical Mechanism of the Vertical Electric Field Generation over Active Tectonic Faults. Advances in Space Research, 44, 767-773. http://dx.doi.org/10.1016/j.asr.2009.04.038

[15] Liu, J.Y., Chen, Y.I. and Chen, C.H., Liu, C.Y., Chen, C.Y., et al. (2009) Seismoionospheric GPS Total Electron Content Anomalies Observed before the 12 May $2008 M_{w} 7.9$ Wenchuan Earthquake. Journal of Geophysical Research A, 114.

[16] Liu, J.Y., Tsai, Y.B. and Ma, K.F. (2006) Precursory Phenomena Associated with the 1999 Chi-Chi Earthquake in Taiwan as Identified under the iSTEP Program. Physics and Chemistry of the Earth, 31, 365-377.

[17] Xia, C.L., Wang, Q., Yu, T., Xu, G.R. and Yang, S.M. (2011) Variations Ionosphere Total Electron Content before Three Strong Earthquakes in the Qinghai-Tibet Region. Advances in Space Research, 47, 506-514. http://dx.doi.org/10.1016/j.asr.2010.09.006

[18] Kelley, M.C. (1989) The Earth’s Ionosphere. Elsevier Press, Amsterdam, 487 p.

[19] Fujinawa, Y. and Takahashi, K. (1990) Emission of Electromagnetic Radiation Preceding the Ito Seismic Swarm of 1989. Nature, 347, 376-378. http://dx.doi.org/10.1038/347376a0

[20] Pulinets, S.A., Boyarchuk, K.A., Hegai, V.V., Kim, V.P. and Lomonosov, A.M. (2000) Quasi-Electrostatic Model of Atmosphere-Thermosphere-Ionosphere Coupling. Advances in Space Research, 26, 1209-1218. http://dx.doi.org/10.1016/S0273-1177(99)01223-5

[21] Liu J.Y., Chen, Y.I. and Chen, C.H. (2009) Seismoionospheric GPS Total Electron Content Anomalies Observed before the 12 May $2008 M_{w} 7.9$ Wenchuan Earthquake. Journal of Geophysical Research A, 114, Article ID: A04320. 
[22] Liu, J.Y., Chen, Y.I., Chuo, Y.J. and Tsai, H.F. (2001) Variations of Ionospheric Total Content during the Chi-Chi Earthquake. Geophysical Research Letters, 28, 1381-1386. http://dx.doi.org/10.1029/2000GL012511

[23] Liu, J.Y., Tsai, Y.B. and Ma, K.F. (2006) Precursory Phenomena Associated with the 1999 Chi-Chi Earthquake in Taiwan as Identified under the iSTEP Program. Physics and Chemistry of the Earth, 31, 365-377. 